\title{
Knowledge Management in the Pharmaceutical Industry: Between Academic Research and Industry Regulations
}

\author{
Ahmed Ramy \\ Technological University Dublin, ahmed.ramy@tudublin.ie \\ Mohamed AF Ragab \\ Technological University Dublin, mohamed.ragab@tudublin.ie \\ Amr Arisha \\ Technological University Dublin, amr.arisha@tudublin.ie
}

Follow this and additional works at: https://arrow.tudublin.ie/buschmanart

Part of the Business Administration, Management, and Operations Commons

\section{Recommended Citation}

Ramy, A. Af Ragab, M. \&Arisha, A. (2020) Knowledge management in the pharmaceutical industry between academic research and industry regulations, Knowledge Management Research \& Practice. doi: $10.1080 / 14778238.2020 .1767517$

This Article is brought to you for free and open access by the School of Management at ARROW@TU Dublin. It has been accepted for inclusion in Articles by an authorized administrator of ARROW@TU Dublin. For more information, please contact arrow.admin@tudublin.ie, aisling.coyne@tudublin.ie,gerard.connolly@tudublin.ie.

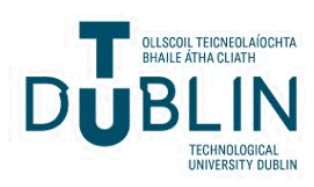




\title{
Knowledge Management in the Pharmaceutical Industry
}

Between Academic Research and Industry Regulations

\author{
Ahmed Ramy* \\ 3S Group - College of Business, \\ Technology University Dublin (TU Dublin), \\ Aungier Street, Dublin 2, Ireland. \\ E-mail: ahmed.ramy@tudublin.ie \\ Tel: +353899724140

\section{Mohamed AF Ragab} \\ 3S Group - College of Business, \\ Technology University Dublin (TU Dublin), \\ Aungier Street, Dublin 2, Ireland. \\ E-mail: mohamed.ragab@tudublin.ie
}

\section{Amr Arisha}

Graduate Business School, College of Business,

Technology University Dublin (TU Dublin), Ireland.

* Corresponding author

\section{Acknowledgement}

The first two authors, Ramy and Ragab, would like to dedicate this paper to the memory of their mentor and third author, Prof. Amr Arisha, who has sadly passed away before the article publishing. He is greatly missed.

\footnotetext{
To cite this article: Ahmed Ramy, Mohamed Af Ragab \& Amr Arisha (2020):

Knowledge management in the pharmaceutical industry between academic

research and industry regulations, Knowledge Management Research \&

Practice, DOI: 10.1080/14778238.2020.1767517

To link to this article: https://doi.org/10.1080/14778238.2020.1767517
} 


\title{
Knowledge Management in the Pharmaceutical Industry \\ Between Academic Research and Industry Regulations
}

\begin{abstract}
The pharmaceutical sector is one of the pillars of the world's economy. A significant proportion of its value lies in intellectual assets generated through continuous innovation and lengthy development cycles within a strictly regulated environment. The purpose of this paper is to address the gap between knowledge management $(\mathrm{KM})$ as an expanding academic discipline in the pharmaceutical industry and at the same time a growing regulatory expectation. A systematic review of 137 refereed KM articles revealed six empirical research themes in the pharmaceutical industry. In a subsequent step, the discovered themes and subthemes were compared with the extant regulatory expectations as explained in 128 regulatory guidelines. Findings shed the light on the gap between academic KM research and the current thinking of regulatory bodies. Some regulated knowledge processes were underrepresented in academic literature. The paper offers also novel insights and recommendations for future developments in academic research, regulations and/or industry.
\end{abstract}

Keywords Knowledge Management, Pharmaceutical Industry, Regulatory, Intellectual Capital, Systematic review, ICH Q10, PRISMA.

Paper type Literature review 


\section{Introduction}

The acknowledgement of knowledge as a pivotal strategic resource in the current smart economy has impelled considerable organisational change. This progressive movement by individuals and organizations to manage their intellectual assets developed into KM (Davenport \& Völpel, 2001). The Pharmaceutical industry is not an exception to this trend, not only as a knowledge-intensive industry but also as a leading economic partner with transcendent investments in innovation and research. According to European Federation of Pharmaceutical Industries and Associations (EFPIA), The Pharmaceutical industry employs more than 750,000 employees in Europe, 16\% of them working in Pharmaceutical Research and Development (R\&D) (EFPIA, 2018).

It is not strange that the significance of $\mathrm{KM}$ is also realized by major pharmaceutical regulatory authorities. International Council for Harmonisation (ICH) recommends management of drug and process knowledge from development and up to product discontinuation as an enabler of effective quality management systems. From this perspective, KM creates the basis for the manufacturing process, control strategy and ongoing continual improvement (ICH, 2009). On the other hand, there are some signs of regulatory immaturity of $\mathrm{KM}$. The term "knowledge" is relatively new in regulatory publications and is routinely replaced by indirect words such as "science" or "product/process understanding" (Calnan et al., 2018). Moreover, KM is seen by ICH only as an enabler of The Pharmaceutical quality system (ICH, 2009).

Thus, as knowledge is another core product of the pharmaceutical industry (Riddell \& Goodman, 2014), managing stocks and flows of knowledge in this sector emerges as a key economic and regulatory objective as well as a growing area of academic research. Nonetheless, some knowledge-intensive industries such as pharmaceuticals have not received adequate attention in industry-specific publications (Ramy et al., 2017). This paper comes as 
a comprehensive industry-specific systematic review of KM literature between the academic research and regulatory expectations.

\section{Review Methodology}

The high expectations of improving the quality of reviews through well-defined methodologies led to the development of systematic review protocols (Jesson et al., 2011). Systematic review protocol encompasses specific research questions, the population that is the focus of the study, the search strategy and terms for identification of the relevant studies. Studies that meet all inclusion criteria and manifest none of the exclusion criteria need to be integrated into the review (Davies \& Crombie, 1998; Tranfield et al., 2003). The authors commenced his review by identifying three research questions:

Q.1 How is the KM literature in pharmaceutical/biopharmaceutical industry developing?

Q 2. What are the expectations of regulatory agencies with regard to the identified research themes?

Q 3. What is the future of KM research within the pharmaceutical industry?

After refining the review questions, the timeframe of review is set to be the last twenty years (1996-2016). This time period represents the prosperous period of KM research (Ragab and Arisha, 2013a). Furthermore, the timeframe took into account the relative novelty of online KM journals. According to Serenko \& Bontis (2013) ranking of the KM journals, the top-ranked four KM journals (JKM, KMRP, IJKM and JIC) have been published online only since 1997, 2003, 2005 and 2000 respectively.

The criteria for inclusion comprise peer-reviewed electronic business journals in the English language retrieved from Emerald Insight and Science Direct database (Table 1). Pharmaceuticals related search strings in the titles, keywords or abstracts were used to identify the relevant articles. Search strings were synthesised by combining terms like "pharmaceutical" or "pharmaceutical industry" with the most popular KM keywords (such 
as knowledge sharing, intellectual capital, knowledge transfer or innovation) extracted from two comprehensive keyword analysis studies in the KM discipline: Fteimi and Lehner (2016) along with Ribière and Walter (2013). After a brainstorming session by the authors, potential search strings were approved. The list was updated during the search process. It was meant not to tightly plan the review process as this may inhibit researchers' capacity to explore, discover and develop ideas (Tranfield et al., 2003).

\section{Table 1 Inclusion and exclusion criteria}

\begin{tabular}{ll}
\hline Inclusion criteria & Exclusion criteria \\
\hline KM theories and processes & Not related to KM \\
With applications in pharmaceutical industry & Applied exclusively in other industries \\
Peer reviewed journal articles & Editorials and position papers \\
In English language & Articles that use languages other than English \\
Published online between 1996 and 2016 & $\begin{array}{l}\text { From journals that don't have online domains } \\
\text { and unpublished work. }\end{array}$ \\
\hline
\end{tabular}

After the exclusion of duplicates, Articles that have been retrieved from the search results were screened against the inclusion and exclusion criteria by reviewing the titles and abstracts (Pati \& Lorusso, 2018). A full-text assessment followed where the full-text articles were scrutinised to assess relevance to the review questions. The retained articles addressed a KM related topic exclusively in the field of pharmaceutical industry or in conjunction with other industries. To mitigate the risk of bias of the reviewed studies (Moher et al., 2015), 141 eligible articles were quality- assessed at for the clarity of research objectives, adequacy of description of the data collection methods and finally the link between data, results and conclusion as advised by Kitchenham and Charters (2007). Four articles were excluded at this stage due to ambiguous methodology and irrelevance to pharmaceutical industry. Ultimately, only 137 articles were retained for analysis after application of inclusion/exclusion criteria and quality assessment. A limited number of non-business journal papers (e.g. medical journals) and papers identified through cross-referencing and hand searching were included (Figure 1). 


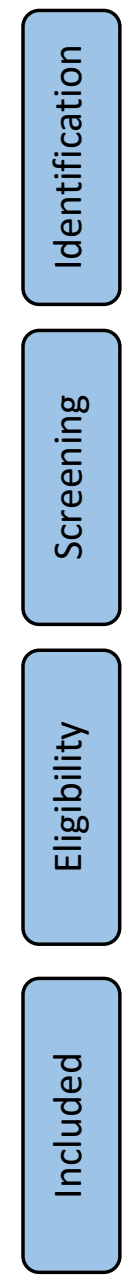

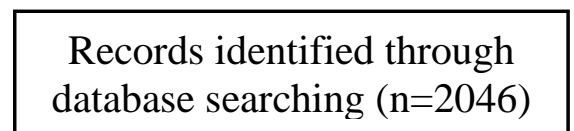

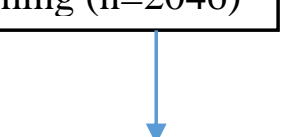

\section{Records after duplicates removed} $(n=1359)$

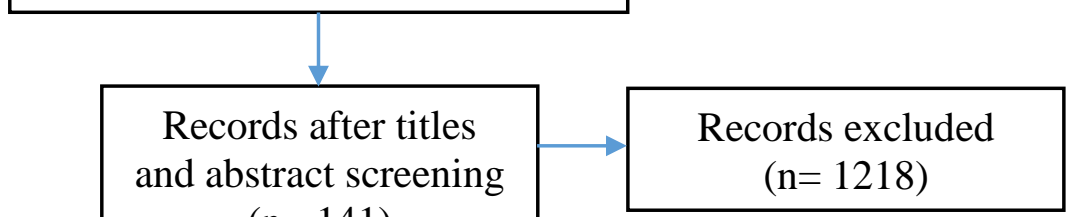

$(n=141)$

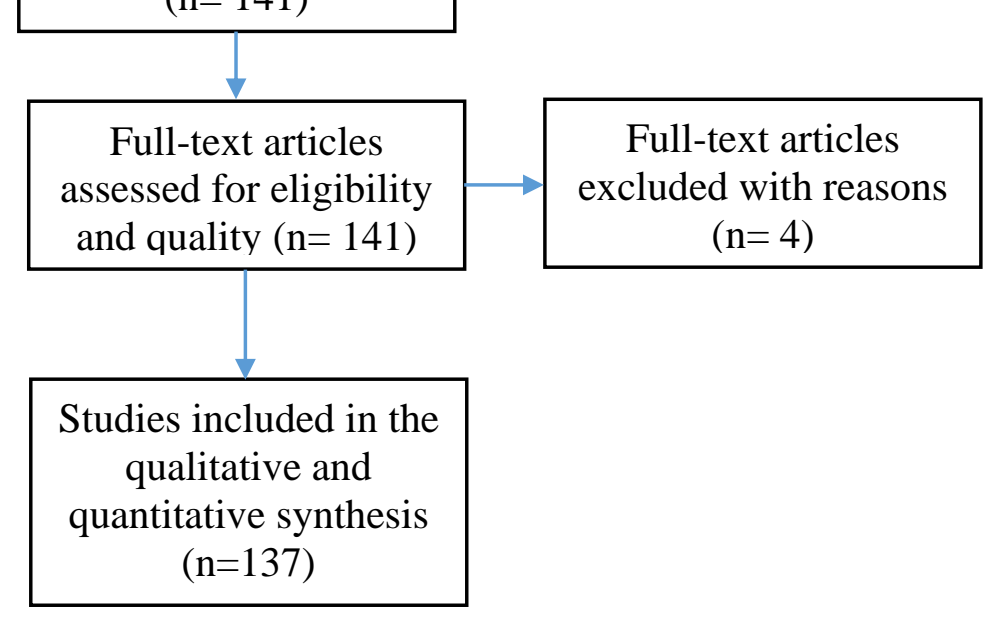

Figure 1 Systematic review process -PRISMA flow diagram (Moher et al., 2015)

After acknowledgement of main themes and processes in $\mathrm{KM}$ literature; the identified themes were scrutinised in the regulatory guidelines of five major regulatory bodies. The reviewer collected all the published guidelines for pharmaceutical industry on the official websites of World Health Organisation (WHO), FDA, ICH, The Pharmaceutical Inspection Convention and Pharmaceutical Inspection Co-operation Scheme (jointly referred to as PIC/S) and Eudralex- European Union (EU) Legislation. AT the end, 128 guidelines were searched for KM related topics in light of the identified themes from academic literature review. The analysis was meant to recognise the significance of research themes from regulatory perspective as well as the possible research gaps in this field. 


\section{Findings}

\section{$\underline{\text { Scientometric Trends }}$}

Initially, findings indicate that $\mathrm{KM}$ in the Pharmaceutical industry has become a wellestablished academic research area. Authorship trends show that approximately $93 \%$ of articles are published by academic researchers, while the remaining $7 \%$ is the product of practitioner work. Over the past ten years, a significant increase in collaborative research from $62 \%$ to $85 \%$ is also evident. Among the articles which do specify the function under study (approx. 40\%), 83\% fall within pharmaceutical development and innovation functions in contrast to only $8 \%$ in production, $4 \%$ in sales and $4 \%$ in supply chain. In order to identify the leading countries in the KM field, the relative contributions of 36 countries whose papers were included in this review are traced and ranked using the Equal Credit counting method (Chua and Cousins 2002; Lowry et al. 2007). The USA and UK were ranked highest with regards to productivity (18\% and $11 \%$ respectively of all reviewed articles); followed by Iran (7\%), Australia (7\%) and India (6\%). It is worth nothing that country contribution in this research addresses the country of residence of the author not necessarily where the research was held (Figure 2).

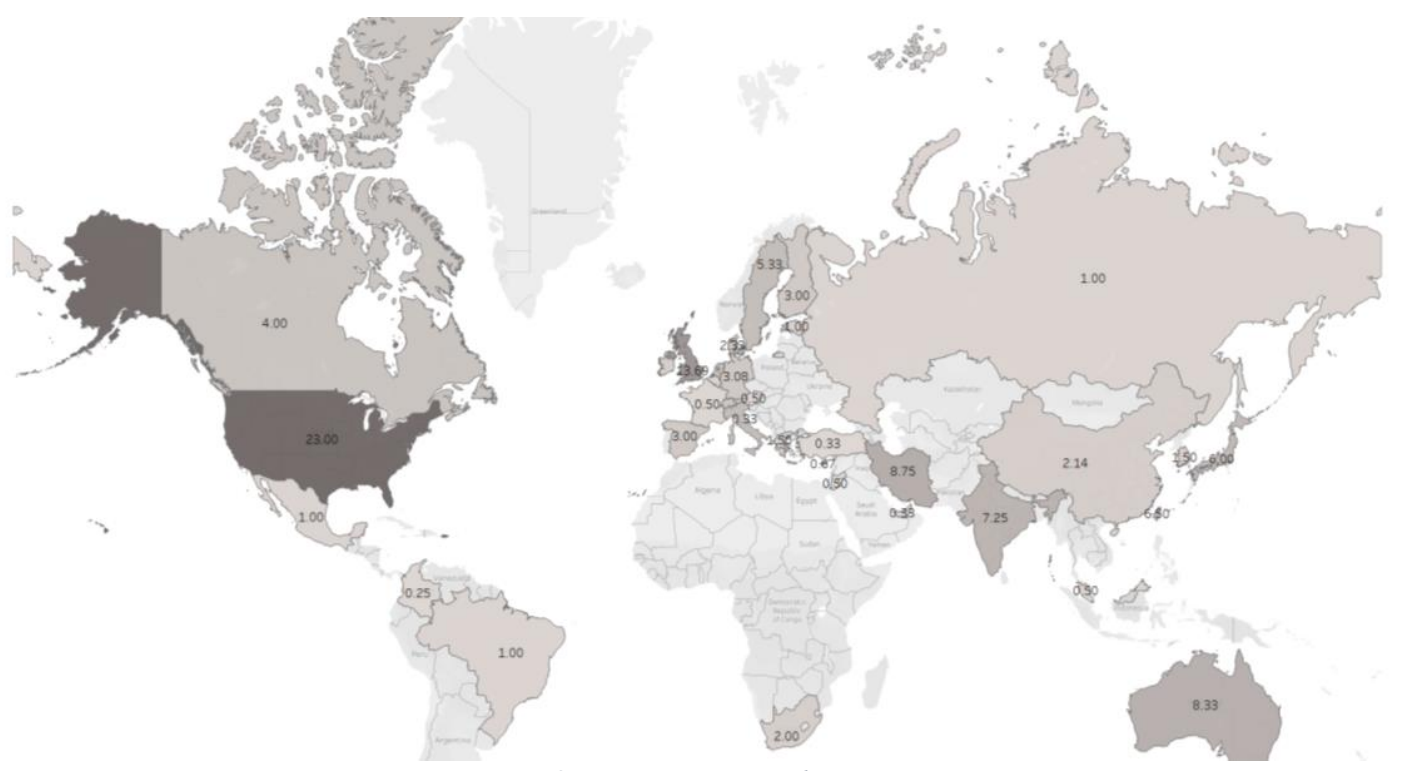

Figure 2 Country productivity 
In terms of methodology, only $29 \%$ of the articles adopt literature review as the research strategy; while over $70 \%$ are empirical studies employing one or more data collection methods e.g. surveys (29\%), case studies (10\%) and interviews (17\%).

\section{$\underline{\text { Research Themes }}$}

A hybrid method of quantitative keyword analysis and qualitative thematic analysis is proposed to identify the common research topics or themes. The most frequent themes and keywords (after exclusion of generic keywords e.g. knowledge management, pharmaceutical...etc.) are presented in (Table 2).

Table 2 Themes and Keyword Analysis

\begin{tabular}{|c|c|c|c|c|}
\hline Rank & Themes \& K. processes & Frequency & Keywords & Frequency \\
\hline $\mathbf{1}$ & Intellectual Capital & 29 & Intellectual Capital & 27 \\
\hline $\mathbf{2}$ & Innovation & 25 & Innovation & 18 \\
\hline $\mathbf{3}$ & Knowledge Transfer & 14 & Knowledge Sharing & 10 \\
\hline $\mathbf{4}$ & Knowledge Sharing & 13 & Knowledge Transfer & 10 \\
\hline $\mathbf{5}$ & Organisational Performance & 12 & New Product Development & 9 \\
\hline $\mathbf{6}$ & Organisational Culture & 12 & Research and Development & 9 \\
\hline $\mathbf{7}$ & Intellectual Property & 10 & Intangible Assets & 8 \\
\hline $\mathbf{8}$ & Knowledge Creation & 9 & Organizational Learning & 7 \\
\hline $\mathbf{9}$ & \multirow{2}{*}{ New Product Development } & 6 & Organizational Culture & 5 \\
\hline $\mathbf{1 0}$ & Organisational Learning & 6 & Project Management & 5 \\
\hline
\end{tabular}

The identified themes and keywords offer a birds-eye view of the KM landscape. The paper presents a classification of KM publications into six areas: knowledge sharing and technology transfer, Intellectual Property Protection (IPP), knowledge measurement and Intellectual capital (IC) reporting, innovation and knowledge creation (KC), organisational knowledge culture and structure as well as Pharmaceutical firm performance (Figure 3). The rest of articles fall in miscellaneous category that includes other themes such as: organisational learning, knowledge management maturity, data mining, etc. Table 3 presents the key articles under each of the featured themes. 

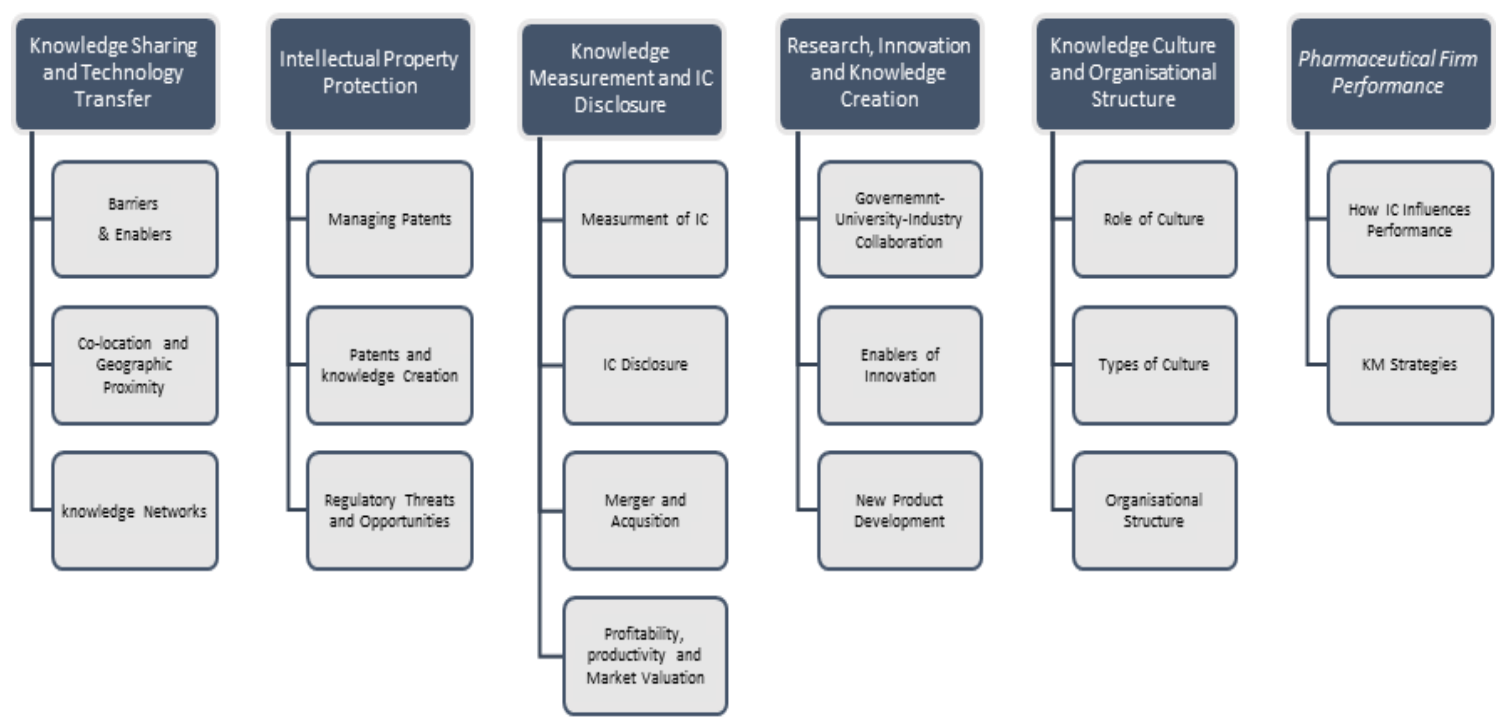

Figure 3 Literature Map

Table 3 Key articles under the featured themes

\section{Category}

Knowledge Sharing and Technology Transfer

Pharmaceutical
Firm Performance
$\begin{aligned} & \text { Research, } \\ & \text { Innovation and } \\ & \text { Knowledge Creation }\end{aligned}$

(Wakefield 2005); (Styhre et al. 2008); (Qureshi and Evans 2015); (Akhavan et al. 2015); (Pedroso and Nakano 2009); (Mets 2006); (Lilleoere and Hansen 2011); (Lawson and Potter 2012); (Hemmert 2004); (Gray, Roth, and Leiblein 2011); (Dooley and Kirk 2007); (Delaney 1999); (Criscuolo 2005); (Coradi, Heinzen, and Boutellier 2015); (Chávez and Víquez 2015); (Brachos et al. 2007); (Bourouni, Noori, and Jafari 2015); (Azan and Huber Sutter 2010); (Allen et al. 2016); (Santos 2003); (Mohan, Jain, and Ramesh 2007); (Malik 2012); (Iwasa and Odagiri 2004); (Filieri et al. 2014); (Chang, Yeh, and Yeh 2007); (Buchel et al. 2013); (Bourouni et al. 2015)

(Mehralian et al. 2012); (Malik 2012); (Kim et al. 2014); (Vishnu and Gupta 2014); (SubbaNarasimha et al. 2003); (Sharabati et al. 2010); (Pal and Soriya 2012); (Kamath 2008); (Garcia Morales, Matias Reche, and HurtadoTorres 2008); (Bollen et al. 2005)

(Terziovski and Morgan 2006); (Styhre et al., 2002); (Sternitzke 2010); (Standing and Kiniti 2011); (Sharma and Goswami 2009); (Roth 2003); (Parisi and Hockerts 2008); (Palacios-Marqués, Popa, and Mari 2016); (O'Dwyer et al. 2015); (Nightingale 2000); (Mehralian et al. 2014); (Lowman et al. 2012); (Lauto and Valentin 2016); (Kneller 2003); (Khemka and Gautam 2010); (Kazadi, Lievens, and Mahr 2015); Kale2005; Huang2011; Hohberger2016; (Herrmann and Peine 2011); (van Geenhuizen and Reyes-Gonzalez 2007); (Gassmann and Reepmeyer 2005); (Garcia Morales et al. 2008); (Filieri et al. 2014); (Chen, Jiao, and Zhao 2008); (Chang et al. 2007); (Cardinal and Hatfield 2000); (Styhre et al. 2008); (Mets 2006); (Lowman et al. 2012); (Lauto and Valentin 2016); (Kazadi et al. 2015); (Gassmann and Reepmeyer 2005); (Cardinal and 


\section{Category}

\section{Intellectual \\ Property Protection}

\section{Knowledge Culture and Organisational Structure}

\section{Knowledge \\ Measurement and IC Disclosure}

Hatfield 2000); (Boasson and Boasson 2015); (Mohan et al. 2007)

(Yang et al. 2014); (Iwasa and Odagiri 2004); (Boasson and Boasson 2015); (Allarakhia and Walsh 2011); (Sternitzke 2010); (Kale and Little 2005); (Hohberger 2016); (Chávez and Víquez 2015); (Russell 2016a); (Bollen, Vergauwen, and Schnieders 2005)

(Wang, Ashleigh, and Meyer 2006); (Mehralian et al. 2016); (MagnierWatanabe and Senoo 2008); (Magnier-Watanabe and Senoo 2010); (Magnier-Watanabe, Benton, and Senoo 2011); (Magnier-Watanabe and Senoo 2009); (Lindner and Wald 2011); (Guzman 2008); (Evans and Brooks 2005); (Ebrahimi, Saives, and Holford 2008); (Bigliardi et al. 2012); (Filieri et al. 2014)

(Vishnu and Kumar Gupta 2014); (Tahvanainen and Hermans 2005); (SubbaNarasimha, Ahmad, and Mallya 2003); (Singh and Kansal 2011); (Sharabati et al. 2010); (Palacios-Marques and Garrigos-Simon 2003); (Pal and Soriya 2012); Narula2016; Naidenova2013; (Mehralian et al. 2013); (Mehralian et al. 2013); (Kamath 2008); (Huang and Wu 2010); (Hine, Helmersson, and Mattsson 2008); (Ghosh and Mondal 2009); (Erickson and Rothberg 2009); (Chizari et al. 2016); (Bollen et al. 2005); (Boekestein 2006); (Boekestein 2009); (Abhayawansa and Azim 2014); (Sydler, Haefliger, and Pruksa 2014); (Russell 2016b); (Rossi, Thrassou, and Vrontis 2015); (Nito 2005); (Mehralian et al. 2012); (Mehralian et al. 2014); (Huang et al. 2011); (Boekestein 2009)

\section{$\underline{\text { Publication years }}$}

The review shows that the majority of included articles have been published between 2004 and 2016 as shown in (Table 4).

Table 4 Publications per year

\begin{tabular}{|c|c|c|c|c|c|c|c|c|}
\hline Year & 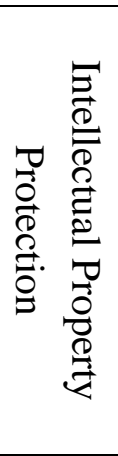 & 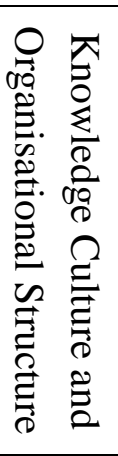 & 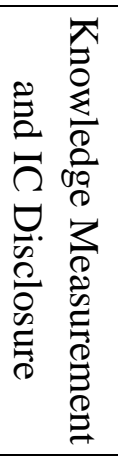 & 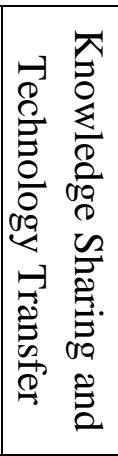 & 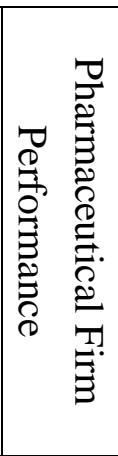 & 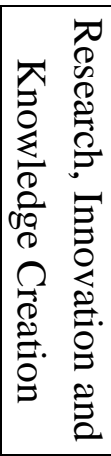 & 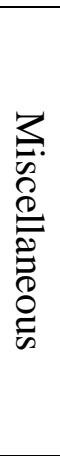 & Total \\
\hline 1996 & & & & & & & 1 & 1 \\
\hline 1997 & & & & & & & 1 & 1 \\
\hline 1998 & & & & & & & 1 & 1 \\
\hline 1999 & & & & 1 & & & & 1 \\
\hline 2000 & & & & & & 3 & 1 & 4 \\
\hline 2001 & & & & & & & & \\
\hline
\end{tabular}




\begin{tabular}{|c|c|c|c|c|c|c|c|c|}
\hline Year & 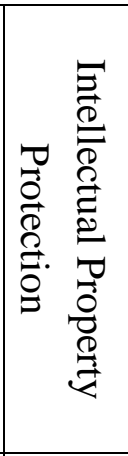 & 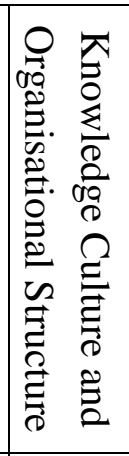 & 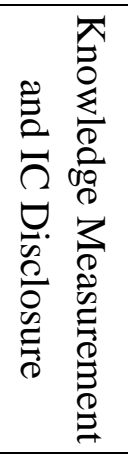 & 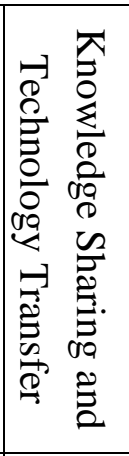 & 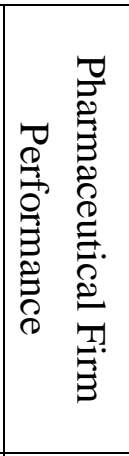 & 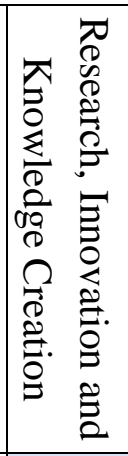 & 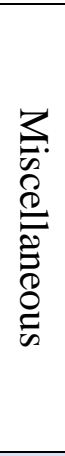 & Total \\
\hline 2002 & & & & & & 1 & 1 & 2 \\
\hline 2003 & & & 2 & 1 & 1 & 2 & 1 & 7 \\
\hline 2004 & 1 & & & 2 & & & 5 & 8 \\
\hline 2005 & 2 & 1 & 3 & 2 & 1 & 3 & 5 & 17 \\
\hline 2006 & & 1 & 1 & 1 & & 2 & 2 & 7 \\
\hline 2007 & & & & 4 & . & 3 & 4 & 11 \\
\hline 2008 & & 3 & 2 & 1 & 2 & 4 & 9 & 21 \\
\hline 2009 & & 1 & 4 & 1 & & 1 & 3 & 10 \\
\hline 2010 & 1 & 1 & 2 & 1 & 1 & 2 & 2 & 10 \\
\hline 2011 & 1 & 2 & 2 & 2 & & 3 & 3 & 13 \\
\hline 2012 & & 1 & 2 & 2 & 3 & 2 & 1 & 11 \\
\hline 2013 & & & 3 & 1 & & & 3 & 7 \\
\hline 2014 & 1 & 1 & 4 & 1 & 2 & 2 & 4 & 15 \\
\hline 2015 & 2 & & 1 & 6 & & 4 & 3 & 16 \\
\hline 2016 & 2 & 1 & 3 & 1 & & 4 & 3 & 14 \\
\hline
\end{tabular}

\subsection{Knowledge Sharing (KS) and Technology Transfer:}

More than $19 \%$ of reviewed articles addressed knowledge sharing and transfer signifying that Knowledge transfer (KT) holds a special significance in the Pharmaceutical industry. Therefore, the WHO dedicates Annex 7 of Technical Report Series no.961 to discuss dynamics and controls of technology transfer occurring at some stage in the lifecycle of most products in the pharma industry. However, the real significance of KS comes from the fact that it is the component that facilitates continuous knowledge creation (Akhavan et al., 2012) and is a key driver of long-term success in a knowledge-intensive organisation (Coradi et al., 2015). Accordingly, Qureshi and Evans (2015) identify nine categories of deterrents of KS in the pharmaceutical organisation. They can be broadly classified as either structural barriers, cultural barriers, or managerial barriers. 
Other studies focused on the attitudes necessary to enhance knowledge sharing (Akhavan et al., 2015). Also, Knowledge Networks (KN) are increasingly considered vital channels to achieve strategic objectives in project-based organisations particularly Pharma R\&D (Bourouni et al., 2015). By the same token, structural indexing and knowledge dictionaries can identify knowledge agents and evaluate intra-organisational knowledge sharing. Enhancing knowledge flow among $R \& D$ stages can be crucial to shorten the product to market timing (Wakefield, 2005).

As physical proximity is one of the suggested barriers for Knowledge Sharing and Technology Transfer (Lilleoere \& Hansen, 2011), several studies handle this topic in pharma explicitly. For instance, studies conducted in the R\&D department of multinational drug manufacturer Novartis reveal that co-location of dispersed project teams leads to faster and more precise flow of knowledge (Coradi et al., 2015).

On a macro scale, an equally significant aspect of inter-organisational KS is geographic distribution. Higher quality risk can accompany offshore manufacturing due to challenges of KT from headquarters (Gray et al., 2011). Pharmaceutical firm location is found to influence the intensity of communication between different firms but not the innovation. Relocation (e.g. into industry clusters) and expensive real estate investments can be replaced by enhancing the social connections through technology (Allen et al., 2016). In spite of that, having an R\&D laboratory near corporate headquarter enhances new drug productivity as proximity is necessary for the integration of $R \& D$ with other functions (Cardinal \& Hatfield, 2000).

\subsection{Intellectual Propriety Protection (IPP):}

There is no industry where firms build their competitive advantage more closely to IPP than the pharmaceutical industry. However, in response to dramatic transitions in bioscience 
and computational chemistry, biopharmaceutical companies commence newer approaches for managing their IP and innovation including open access, exclusive and non-exclusive licensing (Allarakhia \& Walsh, 2011). Although the exclusive licensing is more preferred in the pharmaceutical industry $(2: 1)$, non-exclusive licensing provides a strategic advantage to the company and reduces market uncertainty by decreasing competition (Malik, 2012).

The real significance of IP for the pharmaceutical industry comes from the belief that patents are used as a proxy indicator of knowledge creation (Nerkar, 2003). Also, patent citations studies in pharma exploit patent-related data to estimate the quality of innovation, diffusion of knowledge and geographic localisation of knowledge (Chávez \& Víquez, 2015). For this reason, patents can affirm firm's value and market performance. Association between company value, reported intangible assets and $R \& D$ capitals is proven (Russell, 2016).

In a highly dynamic global economy, enforcing IP protection laws implies significant costs particularly on developing economies (Mazzoleni \& Nelson, 1998). Nevertheless, IPP is an important incentive for innovation in advanced countries enjoying both a superior technological infrastructure as well as a rich market for new drug (WHO, 2006a).

\subsection{Knowledge Measurement and IC Disclosure:}

Empirical evidence supports the notion that the nature and value of knowledge assets differ from industry to another with a direct impact on investment decisions. By using Tobin's Q model for knowledge measurement, it is noticed that not only the level of intellectual capital (IC) and competitive intelligence are both higher in consumer industries (such as pharmaceuticals) in comparison to business to business industries, but also investments in knowledge assets are more promising (Erickson \& Rothberg, 2009). Measurement of pharmaceutical IC at organisational level relies on the identification of most relevant constructs or indicators in each industry (Palacios-Marques \& Garrigos-Simon, 
2003). For example, management experience and technical knowledge are on the top of HC indicators in pharma. Regarding structural capital, organisational culture, the ratio of investment in $R \& D$ and number of $R \& D$ projects are the highest priority indicators. Additionally, mutual trust with customers and their satisfaction are the highest priority RC indicators (Mehralian et al., 2013).

However, the disclosure of IC in balance sheet (BS) is still a measurement barrier and an opportunity for improvement in the pharmaceutical industry, particularly in developing countries. The lack of standardized accounting guidelines on this vital asset results in unreporting of resources of billions in firm's annual reports with impact on their performance in the stock market (Abhayawansa \& Azim, 2014).

Intellectual capital is widely adopted as a predictor for firm's profitability in pharmaceutical sector (Sydler et al., 2014). Healthcare patents reflect firm's innovative capabilities and enhance the capacity to raise necessary start-up capital (WHO, 2006a). However, no significant relationship was observed either between IC and productivity or market valuation (Ghosh \& Mondal, 2009; Pal \& Soriya, 2012). This argument is subject to controversy as companies which generate more profits are able to invest more in IC (Naidenova \& Parshakov, 2013).

In the pharmaceutical industry, Merger and Acquisition (M\&A) is used as cost-effective way to gain access to new product platforms, technologies and patents; traditional pharmaceutical companies with dried-out research pipelines but sufficient cash acquire innovative biotech firm as a source of new products (Rossi et al., 2015). M\&A can be seen as an opportunity to overcome the underestimation of intangible assets under current accounting systems in pharma companies (Boekestein, 2009). 


\subsection{Research, Innovation and knowledge creation $(\mathrm{KC})$ :}

The emergence of new discoveries in the twenty-first century will urge Pharmaceutical manufacturing to employ innovation and cutting-edge technology as ways of doing business (FDA, 2004b). Nowadays, pharmaceutical industries do not typically fit to the classic economy of scales theories as they transformed into $R \& D$ intensive rather than production intensive (Gassmann \& Reepmeyer, 2005). Pharmaceutical industry becomes more than other industries dependent on scientific advances, particularly in basic sciences, developed in public sector (Sternitzke, 2010). Historically, public sector role in drug discovery was limited to basic research to elucidate the basic pathological mechanisms. However, this role has significantly expanded in the biotechnology era (Stevens et al., 2011). In contrast with publically funded drug research model in EU and US universities, it is noticed that drug discovery in Japanese companies occurs predominately in-house which may be no longer compatible with global competitiveness (Kneller, 2003).

In such a complex R\&D environment, information sharing and intrinsic motivation are recognized as important drivers for organizational creativity (Sundgren et al., 2005). There is a significant influence of knowledge transfer on firm innovative capability $(r=0.893)$ too (Palacios-Marqués et al., 2016). As the bulk costs of R\&D come from the clinical phases, sharing knowledge and experiences coming from terminated projects would be of high significance (Styhre et al., 2008).

Surveyed literature highlights some of the dynamics of innovation within pharma organisation. Management support and effective management of knowledge are found indispensable if the organisation wants to adopt an innovative environment. Additionally, Job satisfaction explains up to $25 \%$ of the variance in innovation regression models (Khemka \& Gautam, 2010). Transformational leadership shows a positive relationship with innovation (Garcia Morales et al., 2008). Also, a significant positive relationship is established between 
organisation capital and innovation confirming the remarkable role of intangible assets in generation and enhancement of innovative capabilities (Huang et al., 2011).

Conversely, outsourcing of R\&D and clinical studies for new product development (NPD) and the associated knowledge losses as well as regulatory delays create innovation risks (Lowman et al., 2012). Likewise, FDA warned from the threats of broad interpretations of 21 CFR part 11 (electronic records and electronic signatures) on innovation and technological advances without any benefit for patient health (FDA, 2003).

\subsection{Knowledge Culture and Organisational Structure:}

FDA encourages management to implement quality systems and procedures that support a communicative culture. Under such work culture, employee suggestions are appreciated and used for continual improvement (FDA, 2006). Along the same line, beliefs and knowledgerelated values (love, care and trust) can be potential sources of competitive advantages in pharma (Remy Magnier-Watanabe \& Senoo, 2009).

Knowledge culture is a way of organizational life that empowers people to create, share and use knowledge for the good of the organisation (Oliver \& Kandadi, 2006). In the pharmaceutical industry, knowledge culture is believed to compensate for the lack of organisation memory in temporary project teams where information Communication Technology (ICT) systems are not enough alone for ensuring the exchange of knowledge (Evans \& Brooks, 2005; Lindner \& Wald, 2011). Organisation memory held by aging workers can be transferred to the younger workers through bridges of socialisation and adequate organisational climate (Ebrahimi et al., 2008).

Organisational characteristics of pharmaceutical firm such as structure and strategy affect knowledge acquisition activities including knowledge storage, diffusion and application (Rémy Magnier-Watanabe \& Senoo, 2008). In fact, organisational characteristics can have 
even more influence over KM than national culture (Rémy Magnier-Watanabe \& Senoo, 2010). For example, open culture where employees can raise questions and feel at ease explains $31 \%$ of the variance in four modes of SECI process compared to only $16 \%$ for bureaucratic culture (Rémy Magnier-Watanabe et al., 2011). In pharmaceutical R\&D, bureaucratic culture has a negative impact on knowledge workers' job satisfaction while innovative or supportive culture positively influences them (Bigliardi et al., 2012).

\subsection{Pharmaceutical Firm Performance:}

Human and Relational Capital is deemed to positively impact business performance of the pharmaceutical firm (Sharabati et al., 2010). Several empirical studies have underlined this paradigm utilising either return on asset (ROA) as performance measures (Vishnu \& Gupta, 2014); whereas, Value Added Intellectual Coefficient (VAIC) (Chizari et al., 2016) or generation of new patents were used as proxies for technical knowledge of firms (SubbaNarasimha et al., 2003). Even more striking is the fact that each of the three components of IC is not only individually related to firm performance, but also they collaborate together in the way they influence firm performance (Bollen et al., 2005). KM performance is considered as a predictor of superior financial performance in terms of higher profit ratios (ROA, ROS) and lower cost ratios (OPEX) (Holsapple \& Wu, 2011).

KM strategies can influence organisational performance in pharma. Information system maturity in the pharmaceutical firm as well as knowledge intensity would be the determinants for the most effective KM strategy (Kim et al., 2014). Internal organisational tensions between tacit-oriented and explicit-oriented strategies, which are difficult to reconcile, would negatively impact the performance (Choi et al., 2008). 


\subsection{Regulatory Insights:}

A through exploration of KM in 128 Good Practice (GxP) quality guidelines (Table 5) has revealed a slightly different pattern of interests and expectations in comparison with the academic business journals (Figure 4).

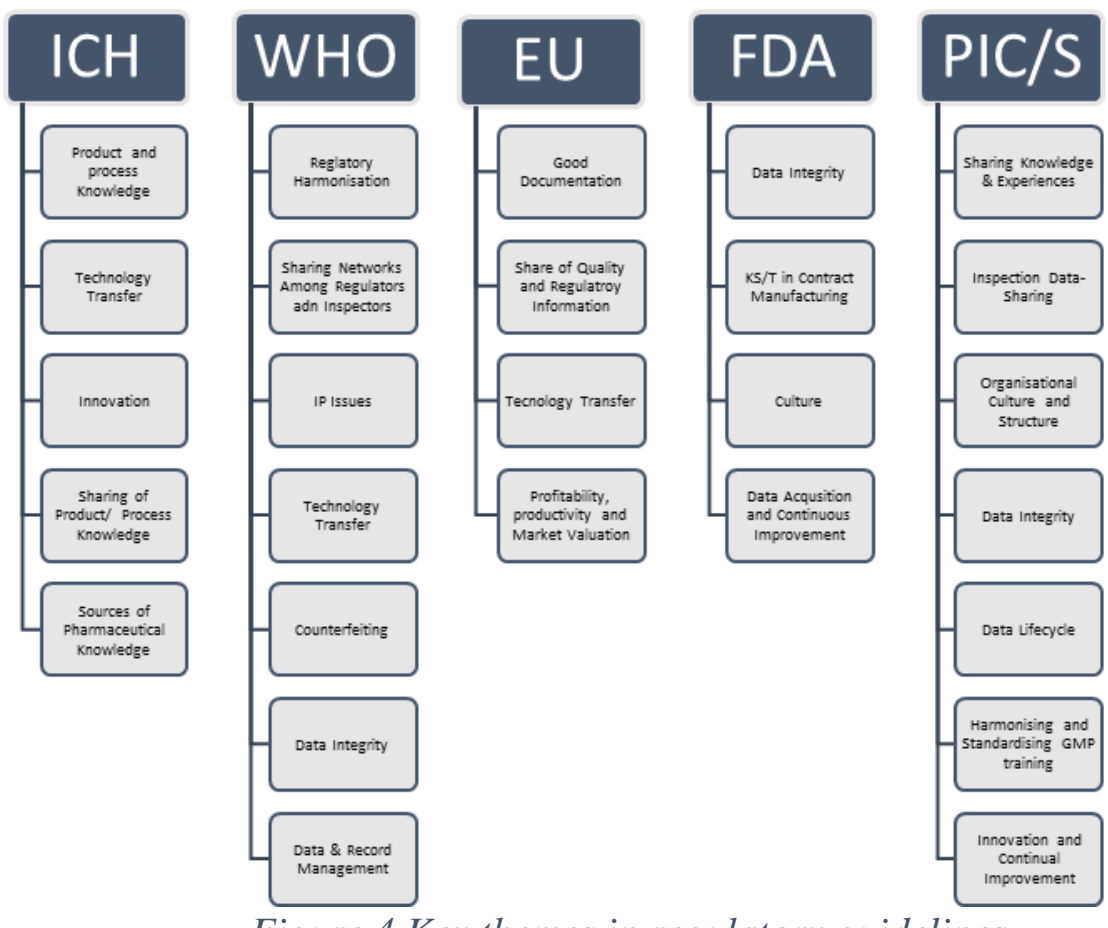

Figure 4 Key themes in regulatory guidelines

An overview of the current thinking and expectations of key regulatory bodies regarding $\mathrm{KM}$ is presented as follow:

\section{$\underline{I C H}$}

From the previous review sections, KM expresses a considerable level of maturity as an academic research field in the pharmaceutical industry. Despite that, KM shows less mature roles at industry level which might hinder the achievement of ICH Q10 desired state (Calnan et al., 2018). KM received meagre attention by regulatory agencies (Rathore et al., 2017). For instance, ICH Q10 considers KM together with QRM as the enablers of its effective implementation throughout the product lifecycle. Proper implementation of ICH Q10 guidelines is deemed necessary for innovation and continual improvement and strengthening the link between pharmaceutical development and manufacturing activities. Last but not 
least, ICH Q10 suggests monitoring of all innovations that might enhance QMS (ICH, 2008). Other ICH guidelines refer sporadically to KM with a focus on KS/KT. ICH Q9 suggested the need for further studies related to technology transfer should be assessed through QRM (ICH, 2005). ICH Q11 endorses the management and sharing of product/process related knowledge throughout product lifecycle including knowledge related to drug substance and its manufacturing process. This is supposed to enhance the manufacturing process and establish a control strategy especially in cases of product ownership changes.

$\underline{W H O}$

For the purpose of earlier detection of potential problems, WHO guidelines pay close attention to regulatory harmonisation and participation in information (e.g. from inspections and clinical studies) sharing networks among regulatory agencies with special considerations to confidentiality and intellectual property issues (e.g. (WHO, 1999, 2003, 2017). Parallel efforts are exerted to contain escalating costs of drug prices by minimizing duplication of inspection activities through: better networking, enhanced collaboration, and increased mutual trust (WHO, 1999). Information sharing efforts with the European Directorate for the Quality of Medicines \& Healthcare (EDQM) extends to certification programs (WHO, 1999). Risk communication and sharing risk related knowledge are also addressed in WHO guidelines (WHO, 2013). Finally yet importantly, sharing public alerts and warning alerts for imported drugs or medical devices can prevent similar faulty products from being exported to other markets (WHO, 2017).

WHO identifies the technology transfer as the middle stage in the drug lifecycle where GMP regulations must apply (WHO, 2013, 2014). The organisation requires validation of the process of data transfer (WHO, 2016). Whenever the transfer involves analytical methods, it is required to conduct this validation by the development before transfer to manufacturing quality control. Periodic checks are necessary to ensure the accuracy and reliability of the 
process (WHO, 2006c). As a general requirement, mechanisms should be addressed to facilitate the transfer of information not only between manufacturers and customers but also to the relevant regulatory bodies (WHO, 2010a).

With regard to IPP, The International Medical Products Anti-Counterfeiting Taskforce (IMPACT) is led by WHO, where the focal point is public health protection from the implications of counterfeiting (WHO, 1999). The ever-changing business strategies and their accompanying intra- and intercompany transfers of technology obliged the WHO Expert Committee on Specifications for Pharmaceutical Preparations in its $42^{\text {nd }}$ report to assign a special guideline to address this issue (TRS 961 Annex 7). However, this guideline is meant to be a flexible framework rather than rigid technology transfer guidance. Although a multifunctional team is proposed to manage the transfer process, it is affirmed to be under the umbrella of a quality system (WHO, 2011).

WHO requires pharmaceutical manufacturers to build their quality decisions and regulatory commitments on science-based understanding of the process and QRM which can offer a greater freedom of how to comply, hence enhances innovation (WHO, 2013). Development of quality culture in the pharmaceutical organisation is believed to improve transparency about failures and ensure good data management strategies are in place. Besides, data integrity and protection occupied a featured position in WHO regulations. Pharmaceutical firms are expected to develop appropriate tools and strategies for the management of data integrity risks based upon their own GxP activities, technologies and processes (WHO, 2016).

\section{$\underline{E U G M P}$}

Furthermore, EU Guidelines for Good Manufacturing Practices (Eudralex) have adopted Good Documentation Practices as an enabling tool for knowledge management throughout 
different stages of product lifecycle (EudraLex, 2015). Similar to WHO, PIC/S and ICH recommendations, the guidelines encourage agents, brokers, distributors, repackers or relabellers to share regulatory and quality information with the manufacturers and customers (Eudralex, 2004; ICH, 2000; PIC/S, 2017; WHO, 2010b). Eudralex requires analytical method transfer protocol (Eudralex, 2006) with no explicit transfer framework as in WHO TRS961 Annex 7. However, it confirmed the coverage of technology transfer by cGMP regulations as a part of product lifecycle (Eudralex, 2011).

$\underline{F D A}$

FDA pays special attention to process understanding and knowledge management as effective strategies for preventing and detecting data integrity issues (FDA, 2016c). On the other hand, FDA accentuates on knowledge sharing and transfer in contract manufacturing as explained in the quality agreement (FDA, 2016a). The agency highlights the role of senior management in the creation of communicative organisational culture as a tool for improving knowledge sharing and communication in addition to cross-functional groups to share ideas for improvement purposes (FDA, 2006).In addition, FDA encourages data acquisition and accumulation over the lifecycle as an important way for continuous improvement which in turn can facilitate the scientific communication with the agency (FDA, 2004a). Similarly, following process validation FDA guidelines would support process improvement and innovation (Services \& FDA, 2011).

\section{$\underline{P I C / S}$}

In response to the increasingly complex global supply chains in the pharma industry, PIC/S facilitates voluntary inspection data-sharing between member authorities. This is deemed to enable risk-based assessment of the need for inspections based on shared confidence in inspected firms (PIC/S, 2011b). It has not escaped our notice that data sharing and transfer in PIC/S guides is focused on inspection data rather than knowledge created in 
pharmaceutical firms. The statute of the International Medicinal Inspectorates Database (IMID), which aims at establishing a database of GMP inspections carried out by IMID participating Regulatory Authorities, was adopted by PIC/S to reduce the number of duplicative inspections (PIC/S, 2012). Besides, the PIC/S committee is cooperating with other global agencies such as WHO, EMA, the ICMRA (International Coalition of Medicines Regulatory Authorities) and United Nations Children's Fund (UNICEF) with regard to training and sharing of inspections' information (PIC/S, 2011a, 2015, 2016b; WHO, 2003).

Because data integrity is essential for successful implementation of GMP, the requirements for good data management are embedded in the current PIC/S guidelines to GMP/GDP for Medicinal products. Good data management practices (GDMP) are envisaged as fundamental enabler for the integrity of the generated data. The manufacturer or distributor undergoing inspection is required to enforce GDMP that ensure the accuracy, completeness and reliability of data (PIC/S, 2016a).

The data lifecycle (from generation till discard at the end of retention period) is also featured in GMP guidelines including data transfer throughout the product lifecycle. In case of computerised systems, interfaces should be assessed and addressed during computer system validation to guarantee the correct, accurate and complete transfer of data (PIC/S, 2016a, 2017). Risk review should be considered specially for supply chains and outsourced activities to assess the extent of data integrity controls required (PIC/S, 2016a). It is noteworthy that PIC/S has repeatedly warned of inappropriate interpretation of guidelines making them barriers to technical innovation or the pursuit of excellence (e.g.PIC/S, 2011c).

Organisational culture and behaviour are a complementary part of the effective data governance system when combined with an understanding of data criticality, data risk and data lifecycle. The value behind this appears in the empowerment of employees to report failures and opportunities for improvement. This reduces the incentive to falsify, alter or 
delete data (PIC/S, 2016a). GMP inspectors have to be sensitive to the effects of organisational culture and structure on the organisation behaviour where data reporting differs between open and close cultures. In order to ensure data integrity within the pharmaceutical organisation, appropriate values, believes, thinking and behaviours need to be demonstrated consistently by management, team leaders and quality personnel (PIC/S, 2016a). 
Table 5 Regulatory insights into Knowledge Management

\begin{tabular}{|c|c|c|c|c|}
\hline KM Theme & EU GMP & $\mathrm{ICH}$ & FDA & WHO \\
\hline $\begin{array}{l}\text { Knowledge } \\
\text { Sharing and } \\
\text { Technology } \\
\text { Transfer: }\end{array}$ & N/A & $\begin{array}{l}\text { ICH Q9 on quality risk } \\
\text { management (4.5.);ICH Q9 on } \\
\text { quality risk management. } \\
\text { (II.3);ICH Good Manufacturing } \\
\text { Practice Guide for Active } \\
\text { Pharmaceutical Ingredients Q7 } \\
\text { (17.60);ICH Q11 - Development } \\
\text { and Manufacture of Drug } \\
\text { Substances (9);ICH Quality Risk } \\
\text { Management Q9 (II.3.);ICH } \\
\text { pharmaceutical quality system } \\
\text { Q10 (1.6.1);ICH pharmaceutical } \\
\text { quality system Q10 (3.1.2) }\end{array}$ & $\begin{array}{l}\text { FDA Guidance for Industry: Contract } \\
\text { Manufacturing Arrangements for Drugs: } \\
\text { Quality Agreements (1.e.); FDA } \\
\text { Guidance for Industry: Contract } \\
\text { Manufacturing Arrangements for } \\
\text { Drugs : Quality Agreements (1.d.); FDA } \\
\text { Guidance for Industry: Contract } \\
\text { Manufacturing Arrangements for } \\
\text { Drugs : Quality Agreements (1.e.); FDA } \\
\text { Guidance for Industry: Quality Systems } \\
\text { Approach to Pharmaceutical CGMP } \\
\text { Regulations (3);CFR Title 21 Part } 820 \\
\text { Quality System Regulations }\end{array}$ & $\begin{array}{l}\text { WHO TRS 1003 Annex } 4 \text { (4.1.1.2.);WHO TRS } 996 \\
\text { Annex } 4 \text { (1.1.);WHO TR S 996 Annex } 1 \text { (4);WHO } \\
\text { TRS1003 Annex } 4 \text { (1.5.);WHO TRS 953 } \\
\text { (2.1.3.);WHO TRS 953 (2.1.9);WHO TRS } 953 \\
\text { (2.1.13);WHO TRS } 953 \text { (8.1);WHO TRS } 953 \\
(8.1 .1) ; \text { WHO TRS 953 (17);WHO TRS } 1003 \text { Annex } 4 \\
\text { (4.2.4.3.);WHO TRS } 1003 \text { Annex } 4 \text { (4.4.);WHO TRS } \\
\text { 981 Annex } 2 \text { (1.1.);WHO TRS 981 Annex } 2 \\
\text { (glossary);WHO TRS 961 Annex 7;WHO TRS } 957 \\
\text { Annex } 2 \text { (17.60);WHO TRS996 Annex 5 (7.6.);WHO } \\
\text { TRS996 Annex 5 (Appendix 1);WHO TRS 973 } \\
\text { Annex } 4 \text { (1.4.);WHO TRS 973 Annex } 4 \text { (3.3.);WHO } \\
\text { TRS 986 Annex } 2 \text { (1.4.);WHO TRS 986 Annex } 2 \\
\text { (7.17);WHO TRS 981 Annex } 2 \text { (1.2.);WHO TRS957 } \\
\text { Annex 5 (14.11);WHO TRS 953 (8.2.) }\end{array}$ \\
\hline IPP & N/A & N/A & N/A & $\begin{array}{l}\text { WHO TRS1003 Annex } 4 \text { (1.6.); WHO TRS } 953 \\
(2.1 .7 ., 2.1 .11)\end{array}$ \\
\hline $\begin{array}{l}\text { Knowledge } \\
\text { Measurement and } \\
\text { IC Disclosure }\end{array}$ & \begin{tabular}{|l|} 
Eudralex \\
Annex 15: \\
Qualification \\
and \\
Validation
\end{tabular} & $\begin{array}{l}\text { ICH pharmaceutical quality } \\
\text { system Q10 (2.8.) }\end{array}$ & $\begin{array}{l}\text { FDA Guidance for Industry: PAT: A } \\
\text { Framework for Innovative } \\
\text { Pharmaceutical Development, } \\
\text { Manufacturing, and Quality Assurance } \\
\text { (1.d.) }\end{array}$ & WHO TRS 961 Annex 7 (1.4) \\
\hline $\begin{array}{l}\text { Research, } \\
\text { Innovation and } \\
\text { Knowledge } \\
\text { Creation }\end{array}$ & N/A & $\begin{array}{l}\text { ICH Q11 - (3.1.3.); ICH Q10 } \\
\text { (Glossary); ICH Q10 (1.1);ICH } \\
\text { Q10 (1.5.3.);ICH Q10 (1.6.);ICH } \\
\text { Q10 (1.6.1.);ICH Q10 (3.2.3.); } \\
\text { ICH Q10 (4.2.b); }\end{array}$ & $\begin{array}{l}\text { FDA Guidance for Industry: Part 11, } \\
\text { Electronic Records; Electronic } \\
\text { Signatures - Scope and Application } \\
\text { (III.B.); FDA Guidance for Industry: } \\
\text { Process Validation : General Principles } \\
\text { and Practices (1);FDA Guidance for } \\
\text { Industry: Data Integrity and Compliance } \\
\text { With CGMP (Draft) (III.1.c) }\end{array}$ & WHO TRS 981 Annex 2 (1.1) \\
\hline $\begin{array}{l}\text { Knowledge } \\
\text { Culture }\end{array}$ & N/A & N/A & $\begin{array}{l}\text { FDA Guidance for Industry: Quality } \\
\text { Systems Approach to Pharmaceutical } \\
\text { CGMP Regulations (B.2.) }\end{array}$ & WHO TRS 996 Annex 5 (1.4.) \\
\hline \begin{tabular}{|l|} 
Pharmaceutical \\
Firm Performance
\end{tabular} & N/A & N/A & N/A & $\begin{array}{l}\text { Knowledge strategies: } \\
\text { WHO TRS } 996 \text { Annex 5 (1.4., 5.4., 5.5.,7.5.) }\end{array}$ \\
\hline
\end{tabular}




\section{4. Discussion and Implications:}

2 The pharmaceutical industry is not only one of the knowledge-intensive sectors, but also

3 an industry with a direct effect on health promotion (Mehralian et al., 2016). It comprises

4 distinct characters making pharmaceutical knowledge management a unique process. Being

5 research-intensive, highly innovative and a great source of IC (Kamath, 2008), building

6 networks of R\&D personnel with research institutions, providing ultimate protection of IP

7 rights, having high influence of political, legal and administrative factors on technology

8 acquisition (Hemmert, 2004), achieving high level of maturity in project management

9 (Wakefield, 2005), involving suppliers in product development activities (Lawson \& Potter,

10 2012), involving collaborative research with universities and governments (Dooley \& Kirk,

11 2007), presenting sophisticated drug discovery and development systems (Criscuolo, 2005),

12 facing challenges of regulated prescription drugs (Pedroso \& Nakano, 2009), being one of the

13 fast growing economic sector (Singh \& Kansal, 2011), together with huge economic

14 productivity and high number of employees (Bigliardi et al., 2012) are some of reasons for

15 choice of pharmaceutical industry as empirical research field in KM literature.

16 Based on an in-depth review of the literature, few trends emerge. Domination of academic

17 authorship (93\% of authors) and empirical research (>70\%) in 36 countries along with $20 \%$

increase in co-authorship reflects the academic maturity of the research area. Participation of practitioners is relatively limited (7\%) in spite of the colossal investments in KM by pharma companies (Riddell \& Goodman, 2014). This also validates the notion that the role which "knowledge" plays in the pharmaceutical industry is still immature and disabling the ICH Q 10 desired pharmaceutical quality system (Calnan et al., 2018). This can also accentuate what has been described by Ragab and Arisha (2013) as a theory-practice gap in KM literature in general. 
1 Since R\&D is considered the key space for knowledge creation (Ingelgård et al., 2002;

2 Parisi et al., 2006), most of the studies ignored other functions (e.g. manufacturing, sales or

3 quality) or other sources of knowledge in pharmaceutical organisation (e.g. process validation

4 studies; manufacturing experience, continual improvement, and change management

5 activities). From a regulatory perspective, managing the knowledge throughout

6 commercialisation and manufacturing phases until product discontinuation is supposed to be

7 as important as managing drug development knowledge (ICH, 2009).

8 Taxonomical analysis of literature affirms six main knowledge processes/ themes

9 extensively covered by researchers (Figure 3). In spite of that, the research in some other

10 potential areas is relatively scarce (e.g. knowledge acquisition). In addition, the current

11 thinking of the pharmaceutical regulatory bodies doesn't match the trending themes in

12 business literature. For example, technology transfer and method/process transfer are

13 regulated practices under pharmaceutical quality systems (ICH, 2009; WHO, 2011); case

14 studies or empirical research is quite limited in this area.

15 IC is the most frequently used keyword and research theme in pharmaceutical KM

16 literature. The influence of pharmaceutical IC on profitability, productivity and market value

17 is addressed in several papers (e.g. Pal and Soriya, 2012). Pharmaceutical IC reporting in BS

suffers from inconsistency and lack of standardised guidelines. Yet, Intellectual Capital,

19 knowledge measurement or disclosure are not recognised by cGMP guidelines. While M\&A

20 implications were a subject of academic research in pharma companies, regulatory

21 publications focus on knowledge transfer after product/process acquisition or data acquisition

22 during product lifecycle (FDA, 2004a).

23 Although KM at product and process level is explicitly required in ICH Q10 1.6.1.(ICH,

24 2008), regulatory authorities didn't suggest any framework for either measurement or

25 disclosure of IC. With poor reporting and disclosure of IC in pharma (Abhayawansa \& Azim, 
1 2014), further research is needed to induce industry-specific measurement frameworks not

2 only at organisational IC level but also at the individual knowledge level. As a part of

3 company intangible capital, patent-related keywords are mentioned 10 times in the review

4 pool (e.g. patent citation, analysis, research, count, etc.) reflecting the importance of IP rights

5 as a research subject.

6 Governmental role in innovation, either through the outputs of basic science or public

7 funding of growing industry $\mathrm{R} \& \mathrm{D}$, is emphasised in the literature. Dynamics of innovation as

8 managed by the Triple Helix model can be a meticulous explication of this phenomenon

9 (Etzkowitz \& Leydesdorff, 2000; Leydesdorff \& Meyer, 2006). When the FDA announced

10 the Pharmaceutical cGMPs for the Twenty-first Century in 2006; corrective actions, innovation and continuous improvement were considered as three complementary improvement approaches in Pharmaceutical Manufacturing (FDA, 2004b). However, only innovation has received enough attention in the surveyed literature. It is worth nothing that the term "creation" was mainly used by the regulators to signify creation of data and/or electronic records (FDA, 2016b).

The review explored the role of pharmaceutical organisational culture and structure in knowledge management. The review confirmed the notion that some values are found to be associated with the prosperity of knowledge within workspace (Remy Magnier-Watanabe \& Senoo, 2009) and a new technology is not able alone to bring about a successful KM system (Chatzkel, 2007). The KM performance of the company was found in general related to its market performance. Unlike pharmaceutical quality system (ICH, 2008), organisational performance as a function of its $\mathrm{KM}$ practices was not considered by any of the four regulatory bodies. 


\section{5. Conclusion and Limitations of Research:}

2 According to the pharmaceutical regulatory guidelines, personnel must be qualified and

3 knowledgeable with functions related to their work activities (FDA, 2006; WHO, 2014). It is

4 a requirement to manage product and process knowledge throughout the product lifecycle

5 (ICH, 2008). However, the academic research interests in pharmaceutical knowledge as

6 presented in the extant KM literature partially overlap with the regulatory concerns. This

7 incomplete overlap offers an opportunity for business researchers to design their future work

8 to help industry meet regulatory expectations. Regulatory bodies recommended knowledge

9 management but did not provide comprehensive frameworks to manage knowledge of

10 pharmaceutical firms at the time industry practitioners refrain from serious contribution to academic research. This supports the notion that knowledge management in pharmaceuticals is still a growing research area, particularly in non-research and development functions.

The review has the limitation of being restricted to articles extracted from the Emerald Insight and Science Direct databases. Knowledge management conference proceeding and other academic portals can be explored in future studies. Despite the limitations, this paper offers an integrative and comprehensive taxonomy of KM literature in an industry-specific context that offers valuable insights for future research. 


\section{$1 \quad$ References}

2 Abhayawansa, S., \& Azim, M. (2014). Corporate reporting of intellectual capital: evidence from the Bangladeshi pharmaceutical sector. Asian Review of Accounting, 22(2), 78-97.

4 Akhavan, P., Ghojavand, S., \& Abdali, R. (2012). Knowledge Sharing and its Impact on Knowledge Creation. Journal of Information \& Knowledge Management, 11(2).

Akhavan, P., Hosseini, S. M., Abbasi, M., \& Manteghi, M. (2015). Knowledge sharing determinants, behaviors, and innovative work behaviors. Leadership \& Organization Development Journal, 24(5), 294-301.

Allarakhia, M., \& Walsh, S. (2011). Managing knowledge assets under conditions of radical change: The case of the pharmaceutical industry. Technovation, 31(2-3), 105-117.

Allen, T. J., Gloor, P. A., Fronzetti Colladon, A., Woerner, S. L., \& Raz, O. (2016). The power of reciprocal knowledge sharing relationships for startup success. Journal of Small Business and Enterprise Development, 23(3), 636-651.

Bigliardi, B., Dormio, A. I., Galati, F., \& Schiuma, G. (2012). The impact of organizational culture on the job satisfaction of knowledge workers. The Journal of Information and

Boasson, V., \& Boasson, E. (2015). Firm value, spatial knowledge flow, and innovation: evidence from patent citations. China Finance Review International, 5(2), 132-160.

Boekestein, B. (2009). Acquisitions reveal the hidden intellectual capital of pharmaceutical companies. Journal of Intellectual Capital, 10(3), 389-400.

Bollen, L., Vergauwen, P., \& Schnieders, S. (2005). Linking intellectual capital and intellectual property to company performance. In Management Decision (Vol. 43, Issue 9). 
1 Bourouni, A., Noori, S., \& Jafari, M. (2015). Knowledge network creation methodology selection in project-based organizations. Aslib Journal of Information Management, 67(1), 74-93.

Calnan, N., Paige, M. J. L., Kane, P. E., \& Menezes, J. C. (2018). A Lifecycle Approach to Knowledge Excellence in the Biopharmaceutical Industry (First). CRC Press.

6 Cardinal, L. B., \& Hatfield, D. E. (2000). Internal knowledge generation: The research laboratory and innovative productivity in the pharmaceutical industry. Journal of Engineering and Technology Management - JET-M, 17(3-4), 247-271.

9 Chatzkel, J. (2007). 2006 KMWorld Conference Review. Journal of Knowledge Management, 11(4), 159-166.

Chávez, G. A. G., \& Víquez, H. G. (2015). Patterns of knowledge flow from industrialized to Latin American and Asian countries in the pharmaceutical industry: A patent citation analysis. Contaduria Y Administracion, 60, 31-56.

Chizari, M. hosein, Mehrjardi, R. Z., Sadrabadi, M. M., \& Mehrjardi, F. K. (2016). The impact of Intellectual Capitals of Pharmaceutical Companies Listed in Tehran Stock Exchange on their Market Performance. Procedia Economics and Finance, 36(16), 291300.

Choi, B., Poon, S. K., \& Davis, J. G. (2008). Effects of knowledge management strategy on organizational performance: A complementarity theory-based approach. Omega The International Journal of Science, 36(2), 235-251.

Chua, C., \& Cousins, K. (2002). Measuring Researcher-Production in Information Systems. $3(1), 145-215$.

Coradi, A., Heinzen, M., \& Boutellier, R. (2015). Designing workspaces for cross-functional knowledge-sharing in R\&D: The "co-location pilot" of novartis. Journal of Knowledge 
2 Criscuolo, P. (2005). On the road again: Researcher mobility inside the R\&D network. Research Policy, 34(9), 1350-1365.

Davenport, T. H., \& Völpel, S. C. (2001). The rise of knowledge towards attention management. Journal of Knowledge Management, 5(3), 212-222.

Davies, H. T., \& Crombie, I. K. (1998). Getting to grips with systematic reviews and metaanalyses. Hospital Medicine (London), 59(12), 955-958.

8 Dooley, L., \& Kirk, D. (2007). University-industry collaboration: Grafting the entrepreneurial paradigm onto academic structures. European Journal of Innovation Management, 10(3), 316-332.

Ebrahimi, M., Saives, A.-L., \& Holford, W. D. (2008). Qualified ageing workers in the knowledge management process of high-tech businesses. Journal of Knowledge Management, 12(2), 124-140.

EFPIA. (2018). The Pharmaceutical Industry in Figures. In European Federation of Pharmaceutical Industries and Associations (EFPIA) Brussels Office.

Erickson, G. S., \& Rothberg, H. N. (2009). Intellectual capital in business-to-business markets. Industrial Marketing Management, 38(2), 159-165.

Etzkowitz, H., \& Leydesdorff, L. (2000). The dynamics of innovation : from National Systems and "“ Mode 2 "” to a Triple Helix of university - industry - government relations. Research Policy, 29, 109-123.

Eudralex. (2004). Part II: Basic Requirements for Active Substances used as Starting Materials. In European Journal of Health Law (Vol. 11, Issue 3).

Eudralex. (2006). Chapter 6: Quality Control. In Health (San Francisco) (Issue June). 
1 Eudralex. (2011). part 1: Chapter 1: Pharmaceutical Quality System (Vol. 4, Issue July).

2 EudraLex. (2015). EudraLex EU Guidelines for Good Manufacturing Practice for Medicinal

3

4

5

6 Products for Human and Veterinary Use, Annex 15: Qualification and Validation (Vol. 4, Issue March).

Evans, J., \& Brooks, L. (2005). Collaborative working in a large pharmaceutical company: Developing better practices through a structurational schema. International Journal of Information Management, 25(6), 551-564.

FDA. (2003). Part 11, Electronic Records; Electronic Signatures — Scope and Application. In FDA Guidance for Industry (Issue August).

FDA. (2004a). Guidance for Industry PAT: A Framework for Innovative Pharmaceutical Development, Manufacuring, and Quality Assurance. In FDA official document (Issue September).

FDA. (2004b). Innovation and Continuous Improvement in Pharmaceutical Manufacturing Pharmaceutical CGMPs for the 21st Century.

FDA. (2006). Guidance for Industry Quality Systems Approach to Pharmaceutical CGMP Regulations (Issue September).

FDA. (2016a). Contract Manufacturing Arrangements for Drugs : Quality Agreements 18 Guidance for Industry (Issue November).

FDA. (2016b). Data Integrity and Compliance With CGMP. In FDA Guidance for Industry (Issue Apri).

FDA. (2016c). Data Integrity and Compliance With CGMP (Draft). In FDA Guidance for Industry (Issue Apri).

Fteimi, N., \& Lehner, F. (2016). Main Research Topics in Knowledge Management: A 
1 Content Analysis of ECKM Publications. Electronic Journal of Knowledge Management, 14(1), 5-17.

3 Garcia Morales, V. J., Matias Reche, F., \& HurtadoTorres, N. (2008). Influence of transformational leadership on organizational innovation and performance depending on the level of organizational learning in the pharmaceutical sector. Journal of OrgChange Mgmt, 21(2), 188-212.

Gassmann, O., \& Reepmeyer, G. (2005). Organizing pharmaceutical innovation: From science-based knowledge creators to drug-oriented knowledge brokers. Creativity and Innovation Management, 14(3), 233-245.

Ghosh, S., \& Mondal, A. (2009). Indian software and pharmaceutical sector IC and financial performance. Journal of Intellectual Capital, 10(3), 369-388.

Gray, J. V., Roth, A. V., \& Leiblein, M. J. (2011). Quality risk in offshore manufacturing: Evidence from the pharmaceutical industry. Journal of Operations Management, 29(78), 737-752.

Hemmert, M. (2004). The influence of institutional factors on the technology acquisition performance of high-tech firms: Survey results from Germany and Japan. Research Policy, 33(6-7), 1019-1039.

Holsapple, C. W., \& Wu, J. (2011). An elusive antecedent of superior firm performance: The knowledge management factor. Decision Support Systems, 52(1), 271-283.

Huang, H. C., Lai, M. C., \& Lin, T. H. (2011). Aligning intangible assets to innovation in biopharmaceutical industry. Expert Systems with Applications, 38(4), 3827-3834.

ICH. (2000). Good Manufacturing Practice Guide for Active Pharmaceutical Ingredients Q7. In ICH Harmonised Trpartite Guideline (Issue November).

ICH. (2005). Quality Risk Management Q9. In ICH Harmonised Tripartite Guideline (Issue 
$1 \quad$ November).

2 ICH. (2008). ICH pharmaceutical quality system Q10. In WHO Drug Information (Vol. 22, 3 Issue 3).

4

5

6

7

ICH. (2009). Guidance for Industry Q10 Pharmaceutical Quality System (Issue April).

ICH. (2012). ICH Q11 - Development and Manufacture of Drug Substances. In Guideline (Issue May).

Ingelgård, A., Roth, J., Styhre, A., \& Shani, a. B. (Rami). (2002). Dynamic learning capability and actionable knowledge creation: clinical R\&D in a pharmaceutical company. The Learning Organization, 9(2), 65-77.

Jesson, J., Matheson, L., \& Lacey, F. M. (2011). Doing Your Literature Review Traditional and Systematic Techniques. In SAGE Publications Ltd.

Kamath, G. B. (2008). Intellectual capital and corporate performance in Indian pharmaceutical industry. Journal of Intellectual Capital, 9(4), 684-704.

Khemka, M., \& Gautam, V. (2010). Innovation in the pharmaceutical industry: study of select parameters. Journal of Advances in Management Research, 7(1), 127-138.

Kim, T. H., Lee, J.-N., Chun, J. U., \& Benbasat, I. (2014). Understanding the effect of knowledge management strategies on knowledge management performance: A contingency perspective. Information \& Management, 51(4), 398-416.

Kitchenham, B., \& Charters, S. (2007). Guidelines for performing Systematic Literature Reviews in Software Engineering.

Kneller, R. (2003). Autarkic drug discovery in Japanese pharmaceutical companies: Insights into national differences in industrial innovation. Research Policy, 32(10), 1805-1827.

Lawson, B., \& Potter, A. (2012). Determinants of knowledge transfer in inter-firm new 
product development projects. International Journal of Operations and Production Management, 32(10), 1228-1247.

Leydesdorff, L., \& Meyer, M. (2006). Triple Helix indicators of knowledge-based innovation systems. Introduction to the special issue. Research Policy, 35(10), 1441-1449.

Lilleoere, A.-M., \& Hansen, E. H. (2011). Knowledge-sharing enablers and barriers in pharmaceutical research and development. Journal of Knowledge Management, 15(1), $53-70$.

Lindner, F., \& Wald, A. (2011). Success factors of knowledge management in temporary organizations. International Journal of Project Management, 29(7), 877-888.

Lowman, M., Trott, P., Hoecht, A., \& Sellam, Z. (2012). Innovation risks of outsourcing in pharmaceutical new product development. Technovation, 32(2), 99-109.

Lowry, P. B., Karuga, G. G., \& Richardson, V. J. (2007). Assessing leading institutions, faculty, and articles in premier information systems research journals. Communications of the Association for Information Systems, 20(16), 142-203.

Magnier-Watanabe, R., Benton, C., \& Senoo, D. (2011). A study of knowledge management enablers across countries. Knowledge Management Research \& Practice, 9(1), 17-28.

Magnier-Watanabe, R., \& Senoo, D. (2008). Organizational characteristics as prescriptive factors of knowledge management initiatives. Journal of Knowledge Management, 12(1), 21-36*.

Magnier-Watanabe, R., \& Senoo, D. (2009). Congruent knowledge management behaviors as discriminate sources of competitive advantage. Journal of Workplace Learning, 21(2), $109-124$.

Magnier-Watanabe, R., \& Senoo, D. (2010). Shaping knowledge management: organization and national culture. Journal of Knowledge Management, 14(2), 214-227. 
1 Malik, T. (2012). Non-exclusive attention-structure for inter-organizational knowledge flow and performance of the pharmaceutical firm. Journal of Knowledge-Based Innovation in China, 4(1), 18-35.

Mazzoleni, R., \& Nelson, R. R. (1998). The benefits and costs of strong patent protection: a contribution to the current debate. Research Policy, 27(3), 273-284.

Mehralian, G., Nazari, J. A., Rasekh, H. R., \& Hosseini, S. (2016). TOPSIS approach to prioritize critical success factors of TQM. The TQM Journal, 28(2), 235-249.

Mehralian, G., Rajabzadeh, A., Sadeh, M. R., \& Rasekh, H. R. (2012). Intellectual capital and corporate performance in Iranian pharmaceutical industry. Journal of Intellectual Capital, 13(1), 138-158.

Mehralian, G., Rasekh, H. R., Akhavan, P., \& Ghatari, A. R. (2013). Prioritization of intellectual capital indicators in knowledge-based industries: Evidence from pharmaceutical industry. International Journal of Information Management, 33(1), 209216.

Moher, D., Shamseer, L., Clarke, M., Ghersi, D., Liberati, A., Petticrew, M., Shekelle, P., \& Stewart, L. A. (2015). Preferred reporting items for systematic review and meta-analysis protocols (prisma-p) 2015 statement. Japanese Pharmacology and Therapeutics, 47(8), $1177-1185$.

Naidenova, I., \& Parshakov, P. (2013). Intellectual capital investments: Evidence from panel VAR analysis. Journal of Intellectual Capital, 14(4), 634-660.

Nerkar, A. (2003). Old Is Gold? The Value of Temporal Exploration in the Creation of New Knowledge. Management Science, 49(2), 211-229.

Oliver, S., \& Kandadi, K. R. (2006). How to develop knowledge culture in organizations? A multiple case study of large distributed organizations. Journal of Knowledge 
Pal, K., \& Soriya, S. (2012). IC performance of Indian pharmaceutical and textile industry. Journal of Intellectual Capital, 13(1), 120-137.

4 Palacios-Marques, D., \& Garrigos-Simon, F. J. (2003). Validating and measuring IC in the biotechnology and telecommunication industries. Journal of Intellectual Capital, 4(3),

6

Parisi, M. L., Schiantarelli, F., \& Sembenelli, A. (2006). Productivity, innovation and R\&D: Micro evidence for Italy. European Economic Review, 50(8), 2037-2061.

Pati, D., \& Lorusso, L. N. (2018). How to Write a Systematic Review of the Literature. Health Environments Research and Design Journal, 11(1), 15-30.

Pedroso, M. C., \& Nakano, D. (2009). Knowledge and information flows in supply chains: A study on pharmaceutical companies. International Journal of Production Economics, 122(1), 376-384.

PIC/S. (2011a). Annual Report 2010 (Issue March).

PIC/S. (2011b). Pharmaceutical inspection co-operation scheme (Vol. 95, Issue March).

PIC/S. (2011c). Validation of Aseptic Processes. In Pharmaceutical Inspection Convention Pharmaceutical Inspection Co-Operation Scheme: Vol. PI007-6 (Issue January).

PIC/S. (2012). Press release. In Pharmaceutical Inspection Convention Pharmaceutical Inspection Co-Operation Scheme (Vol. 37, Issue February).

PIC/S. (2015). Press Release Pic / S Meetings (Vol. 7, Issue November 2013). 
1 PIC/S. (2016a). Good Practices for Data Management and Integrity in Regulated Gmp/Gdp Environments. In Journal of Chemical Information and Modeling (Vol. 1, Issue August).

PIC/S. (2016b). Press Release : PIC / S Meetings In Geneva ( Switzerland) Executive Bureau and China Food and Drug Administration ( CFDA ). PIC / S strenghtens international regulatory co-operation in the field of GMP (Issue May 2015).

PIC/S. (2017). Guide To Good Manufacturing Practice for Medicinal Products Part II: Vol. PE 009-13 (Issue January).

Qureshi, A. M. A., \& Evans, N. (2015). Deterrents to knowledge-sharing in the pharmaceutical industry: a case study. Journal of Knowledge Management, 19(2), 296314.

Ragab, M. A. F., \& Arisha, A. (2013). Knowledge management and measurement: a critical review. Journal of Knowledge Management, 17(6), 873-901.

Ragab, M., \& Arisha, A. (2013). The MinK framework: towards measuring individual knowledge. Knowledge Management Research \& Practice, 13(2), 1-9.

Ramy, A., Floody, J., Ragab, M. A. F., Arisha, A., \& Schiuma, G. (2017). Scientometric Analysis of Knowledge Management Research and Practice (KMRP): 2003 -2015. 12th International Forum on Knowledge Asset Dynamics, 1-24.

Rathore, A. S., Garcia-Aponte, O. F., Golabgir, A., Vallejo-Diaz, B. M., \& Herwig, C. (2017). Role of Knowledge Management in Development and Lifecycle Management of Biopharmaceuticals. Pharmaceutical Research, 34(2), 243-256.

Ribière, V., \& Walter, C. (2013). 10 years of KM theory and practices. Knowledge Management Research Practice, 11(1), 4-9.

Riddell, J., \& Goodman, E. (2014). Knowledge Management in the Pharmaceutical Industry: 
Enhancing Research, Development and Manufacturing Performance. Ashgate Publishing Limited.

Rossi, M., Thrassou, A., \& Vrontis, D. (2015). Biotechnological mergers and acquisitions: features, trends and new dynamics. Journal of Research in Marketing and Entrepreneurship, 17(1), 91-109.

Roth, J. (2003). Enabling knowledge creation: learning from an R\&D organization. Journal of Knowledge Management, 7(1), 32-48.

Russell, M. (2016). The Valuation of Pharmaceutical Intangibles. Journal of Intellectual Capital, 17(May 2015), 1-37.

Serenko, A., \& Bontis, N. (2013). Global ranking of knowledge management and intellectual capital academic journals: 2013 update. Journal of Knowledge Management, 17(2), $307-326$.

Services, H., \& FDA. (2011). Guidance for Industry Process Validation : General Principles and Practices Guidance for Industry Process Validation : General Principles and Practices. In Quality (Issue January).

Sharabati, A.-A. A., Jawad, S. N., Bontis, N., Naji Jawad, S., \& Bontis, N. (2010). Intellectual capital and business performance in the pharmaceutical sector of Jordan. Management Decision, 48(1), 105-131.

Singh, S., \& Kansal, M. (2011). Voluntary disclosures of intellectual capital. Journal of Intellectual Capital, 12(2), 301-318.

Sternitzke, C. (2010). Knowledge sources, patent protection, and commercialization of pharmaceutical innovations. Research Policy, 39(6), 810-821.

Stevens, A. J., Jensen, J. J., Wyller, K., Kilgore, P. C., Chatterjee, S., \& Rohrbaugh, M. L. (2011). The Role of Public-Sector Research in the Discovery of Drugs and Vaccines. 
Styhre, A., Ollila, S., Roth, J., Williamson, D., \& Berg, L. (2008). Heedful interrelating, knowledge sharing, and new drug development. Journal of Knowledge Management, $12(3), 127-140$.

SubbaNarasimha, P. N., Ahmad, S., \& Mallya, S. N. (2003). Technological knowledge and firm performance of pharmaceutical firms. Journal of Intellectual Capital, 4(1), 20-33.

Sundgren, M., Dimena, E., Gustafsson, J., \& Selart, M. (2005). Drivers of organizational creativity: a path model of creative climate in pharmaceutical R \& D. $R \& D$ Management, 35(4).

Sydler, R., Haefliger, S., \& Pruksa, R. (2014). Measuring intellectual capital with financial figures: Can we predict firm profitability? European Management Journal, 32(2), 244259.

Tranfield, D., Denyer, D., \& Smart, P. (2003). Towards a methodology for developing evidence-informed management knowledge by means of systematic review *. British Journal of Management, 14(September), 207-222.

Vishnu, S., \& Gupta, V. K. (2014). Intellectual capital and performance of pharmaceutical firms in India. Journal of Intellectual Capital, 15(1), 83-99.

Wakefield, R. L. (2005). Identifying knowledge agents in a KM strategy: The use of the structural influence index. Information and Management, 42(7), 935-945.

WHO. (1999). TRS 953 WHO Expert Committee on Specifications for Pharmaceutical Preparations : thirty-fifth report. In WHO technical report series (Issue 885).

WHO. (2003). TRS1003 Annex 4 Procedure for assessing the acceptability, in principle , of quality control laboratories for use by United Nations agencies (Issue 917). 
1 WHO. (2006a). Public health innovation and intellectual property rights: report of the Commission on Intellectual Property Rights, Innovation and Public Health. In WHO Library Cataloguing-in-Publication Data Commission.

WHO. (2006b). TR S 996 Annex 1 Good pharmacopoeial practices (Issue Icc).

WHO. (2006c). TRS 973 Annex 4 Supplementary guidelines on good manufacturing practices : validation. In WHO technical report series (Vol. 937, Issue 937).

WHO. (2010a). TRS957 Annex 5 WHO good distribution practices for pharmaceutical products. In WHO Technical Report Series (Issue 957).

WHO. (2010b). TRS 957 Annex 2 good manufacturing practices for active pharmaceutical ingredients. In WHO Technical Report Series (Vol. 957, Issue Annex 2).

WHO. (2011). Annex 7: WHO guidelines on transfer of technology in pharmaceutical manufacturing. In $W H O$ (Issue 961).

WHO. (2013). TRS 981 Annex 2 guidelines on quality risk management.

WHO. (2014). TRS 986 Annex 2 WHO good manufacturing practices for pharmaceutical products: main principles. In WHO (World Health Organization. Technical Report Series, No. 961. (Issue 961).

WHO. (2016). TRS996 Annex 5 Guidance on good data and record management practices. In WHO Technical Report Series (Issue 996).

WHO. (2017). TRS 1003 Annex 4 WHO Global Model Regulatory Framework for Medical Devices including in vitro diagnostic medical devices. WHO Medical device technical series. 